\title{
EXPERIMENTAL STUDY OF HOT WATER STORAGE TANKS FROM A DOMESTIC REFRIGERATOR
}

\begin{abstract}
I. M. Neto ${ }^{\mathrm{a}}$, ABSTRACT
S. D. R. Oliveira ${ }^{a}$,

A. Padilha ${ }^{a}$, and V. L. Scalon ${ }^{\mathrm{a}}$

${ }^{a}$ Universidade Estadual Paulista Júlio de Mesquita Filho - UNESP Departamento de Engenharia Mecânica Bauru, São Paulo, Brasil ismael_marchi@yahoo.com.br

The extreme necessity to diversify the sources of renewable energy motivates the search for methods of recycling of thermal energy losses of equipments. Thus, these energy losses can be used as a new source of energy for water heating and storage in a Domestic Hot Water Storage Tank (DHWST). Therefore, an experimental apparatus is proposed with a cylindrical tank for liquid storage. The main objective of this experimental test is the estimation of the coefficient of comprehensive energy performance (COP) relative to the system and the analysis of the hot water storage through the stratification technique. The storage and use of this form of energy utilizes a shell and tube heat exchanger, whose function is to condensate the cooling liquid using water in countercurrent, which substitutes the refrigerator finned condenser. Thermal energy losses are collected by the thermosiphon principle, and stored as sensible heat in the tank. The results showed the full operation of the modified refrigeration system as well as the storage of hot water at satisfactory thermal levels for domestic use, since this is a commercially manufactured refrigerator.
\end{abstract}

Keywords: coefficient of energy performance, thermal stratification, storage tanks, thermal energy losses, domestic refrigerator.

\section{NOMENCLATURE}

A $\quad$ area, $\mathrm{m}^{2}$

COP coefficient of performance

COPS coefficient of system performance

$\mathrm{C}_{\mathrm{p}}$ fluid specific heat at constant pressure, $\mathrm{J} /(\mathrm{kg} \cdot \mathrm{K})$

$\mathrm{K}$ fluid thermal conductivity, W/(m.K)

$\mathrm{q}$ heat transfer rate, $\mathrm{W}$

$\mathrm{Q}_{\mathrm{H}}$ heat transferred to the modified heat exchanger, $\mathrm{J}$

$\mathrm{Q}_{\mathrm{L}} \quad$ heat removed from the compartment, $\mathrm{J}$

$\mathrm{t}^{\mathrm{C}} \quad$ load time, $\mathrm{s}$

W wasted energy, W

\section{Greek symbols}

$\rho \quad$ density, $\mathrm{kg} / \mathrm{m}^{3}$

\section{Subscripts}

air air

Pt heat losses

$\mathrm{Pt}_{\mathrm{F}} \quad$ heat losses from the freezer

$\mathrm{Pt}_{\mathrm{R}}$ heat losses from the refrigerator

\section{INTRODUCTION}

As of the beginning of the 20th century, the natural resources have been intensely extracted, ignoring their impoverishment, the air pollution and the soil degradation. The world has gone through severe energetic crisis. This way, the use of traditional energy sources projects its path toward their decline and the search for new alternative energy sources is intensifying, as mankind is getting more and more concerned with the environment.

By using renewable energy sources, mankind contributes to the decrease of the environmental pollution, to the improvement in the people's quality of life and also to the availability of natural resources for future generations. In addition, it can contribute positively to soften the climate alteration phenomenon, specifically the global warming issue.

For a "domestic" use, there are various types of renewable sources, specially the thermal solar, the photovoltaic solar and the biomass energy, such as the ones that present greater performance feasibility in any type of building, either urban or rural. When utilizing such non-conventional systems for the use of energy, it is fundamental that the thermal energy be stored. This same procedure has a random aspect to its characteristics and adequate dimensions, varying according to the region's climatic conditions, to the solar radiation and to the type of application for the energy conversion system.

By means of a energy balance to the storage system, Padilha (1982) proposed a semi-empirical, unidimensional and transient model, from which it was obtained the development for the thermally stratified liquid temperature and its wall, during the charge, discharge and natural cooling period. It was also verified the influence of the height/diameter relation of the thermal storage on the thermal stratification efficiency by the First and Second Law of Thermodynamics, in addition to comparing the 
theoretical results with the experimental ones available in the literature.

Kandari (1990) analyzed the results of the experimental study on the thermal stratification in hot water storage tanks, by means of a solar collector. An experimental model at a scale of 1:25 by volume was built in order to study the effect of the most adequate geometry of inlet to the distributor. The results showed that the dense disturbance zone is of approximately $30 \%$ of the height of the thermal storage and the extraction efficiencies for the loading and unloading processes can be obtained between the range of $73 \%$ to $85 \%$.

Trillat-Berdal, Souyre and Fraisse (2006) presented an experimental study of geothermal heat pumps coupled to a solar collector. This process is named GEOSOL, which consists of storing hot water in a tank and using part of this energy to heat or cool a specific environment based on a heat pump, properly coupled to the system. After 11 months of operation, the energy extracted and injected into the soil presented the mean values of 40.3 and $39.5 \mathrm{~W} / \mathrm{m}$, respectively. The energy injected in the soil represented $34 \%$ of the thermal energy extracted and the Coefficient of Performance (COP) of the heat pump for the heating presented an mean value of 3.75. The experimental study showed the combination of renewable energies, such as the solar and the geothermal energies, in a single system, can be utilized in a house, thus guaranteeing a satisfactory level of comfort, in addition to low electrical energy consumption.

As for the use of a modified air conditioner, Jiang et al. (2006) developed an experimental study aiming at recovering the energy dispersed by the condenser and reutilizing it as an energy source for the heating of water contained in a thermal tank. This way, a thermal storage was utilized, containing a spiral condenser, where the coolant exchanges energy with the stored water in the interior of the tank. The results showed that the modified air conditioning system can be used to heat the domestic hot water without losing its refrigeration capacity, by presenting a performance coefficient of $38.6 \%$ higher, when compared to the originally designed air conditioning system.

At the first stage of this research, FernándezSeara, Uhía and Sieres (2007) carried out experimental tests in domestic hot water thermal storages, in which it was analyzed the static mode of operation of a tank with capacity of up to 150 liters. The main objective of the research was to observe the storage tank behavior in the heating and cooling period, in order to characterize its performance by means of the energy and exergy analysis, via the thermal stratification technique. In the second stage, the same tanks were equipped with different types of inlets and outlets, and the operation mode was altered from static to dynamic. The analysis based on a distribution of transient temperature to the inlet and outlet of water, and the temperature fields were obtained from the utilization of thermocouples introduced in the interior of the thermal storage for posterior processing, based on data acquisition equipment. By means of the energetic and exergetic analysis, it was possible to identify the most adequate configuration of the thermal storages proposed for practical use.

One can conclude that only from the late 60 s the thermal storage started to have proper consideration by several researchers, due to its increasing applicability to conservation and energy use systems. Thus, this type of storage became a very recent topic for research and development. Despite its large applicability, there is not a well-defined project topology yet. Therefore, there is a need for a great theoretical and experimental effort in order to understand it completely (Padilha, 1983).

\section{DESCRIPTION OF THE DHWST PROCESS}

The experimental apparatus consists of one duplex domestic refrigerator of 263 liters for the cooling cabinet and 74 liters for the freezing cabinet. The same had of its condensers replaced with a heat exchanger, such as the shell and tube in countercurrent (Amaral Filho, 2005), whose function is to condense the refrigerant gas by using circulating water that will replace the refrigerator's finned condenser. The heated water is then injected by the thermosiphon principle, at the top of the 122 liter cylindrical thermal storage, formed by a 0.3 meter diameter PVC tube of $1.75 \mathrm{~m}$ high and $4 \mathrm{~mm}$ of thickness, where it is stored by thermal stratification technique.

In order to measure the temperature, type $\mathrm{T}$ thermocouples were used (copper-constantan), in which were properly calibrated by using a standard thermometer coupled to a thermal bath equipment. After the calibration of the thermocouples, it was necessary to obtain the temperature fields in the interior of the thermal storage. For this purpose, it was built a probe containing 31 thermocouples all over it, so that several temperature points along the thermal storage extension could be obtained.

In addition to using thermocouples in the interior of the thermal storage, it is necessary to distribute some of these across other areas in order to obtain a thorough monitoring of the system, composed of thermal storage and refrigerator. This way, five thermocouples are present in the following regions: Inlet and outlet of the modified condenser of the refrigerator; the refrigerator and freezer cabinets. Then, a thermocouple is placed in order to obtain room temperature.

After all the system - refrigerator and thermal storage - is properly coupled, the thermocouples were connected to a data acquisition Logoscreen graphic recorder with six mTron Jumo expansers, in which all the information was collected and stored 
via serial cable by means of a computer. The data in binary format will be collected with the use a JumoPCC software and decodified by using a JumoPCA software, which accompanies the equipment, and transferred to an electronic worksheet for future use.

Based on the data achieved by means of the electronic worksheet, the refrigerators' Performance Coefficient will be obtained, in addition to analyzing the hot water storage, via thermal stratification technique. The schematic diagram of the DHWST process is presented in Fig. 1.

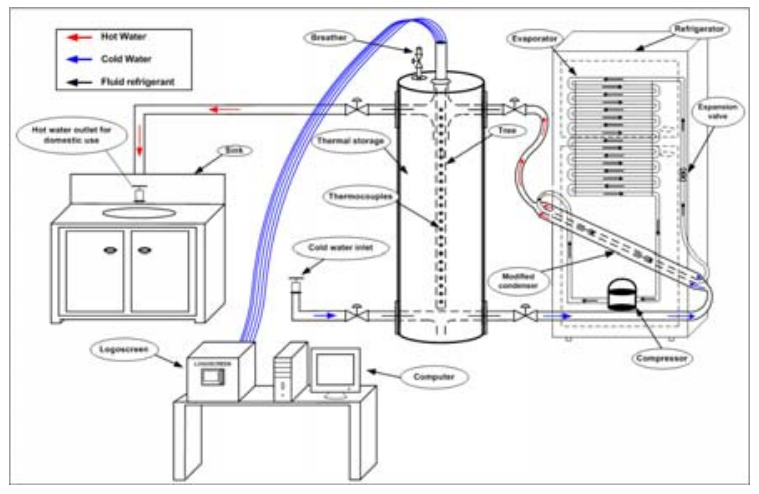

Figure 1. Schematic diagram of the DHWST process.

\section{DETERMINATION OF COP REFERRING TO THE REFRIGERATOR}

A refrigerator or heat pump is a device that operates according to a cycle and needs work, so that it can obtain transfer of heat from a low temperature to a high temperature in a specific body, (Van Wylen et al., 2003). This way, for the present research, the refrigerator is provided with electric energy, and the heat $\left(\mathrm{Q}_{\mathrm{L}}\right)$ is transferred from the refrigerated area to the modified heat exchanger $\left(\mathrm{Q}_{\mathrm{H}}\right)$, where part of it is transferred to the water and stored in the thermal storages by thermal stratification.

The concept for the performance index of a refrigeration cycle is expressed in terms of the Coefficient of Performance (COP), which consists here of the ratio between the intended energy $\left(\mathrm{Q}_{\mathrm{L}}\right)$ and the wasted energy (W), (Stoecker and Jones, 1985). Thus, one can state that:

$$
\mathrm{COP}=\frac{\mathrm{Q}_{\mathrm{L}}}{\mathrm{W}}
$$

However, the coefficient of system performance (COPS) proposed in this study differs from the COP found in literature due to the analysis' experimental nature, which showed $\mathrm{Q}_{\mathrm{L}}$ and $\mathrm{W}$ as estimates. Thus, in order to determine useful refrigeration $\left(\mathrm{Q}_{\mathrm{L}}\right)$, it becomes necessary to calculate the amount of heat removed from the refrigerator's $\left(Q_{R}\right)$ freezer compartment $\left(\mathrm{Q}_{\mathrm{F}}\right)$ and then estimate the heat loss transfer rate $\left(\mathrm{q}_{\mathrm{Pt}}\right)$, which enters the refrigerator through the temperature difference between the refrigerated compartment and the environment. This is because despite the refrigerator walls having adequate isolation thermal, the heat flow increases with time as the compressor removes the heat from inside the refrigerator.

In order to determine useful refrigeration $\left(\mathrm{Q}_{\mathrm{L}}\right)$, it becomes necessary to calculate the amount of heat removed from the freezer compartment $\left(\mathrm{Q}_{\mathrm{F}}\right)$ and the refrigerator $\left(Q_{R}\right)$ using Eq. (2) and (3), with the thermocouples located in the air inside the freezer and refrigerator compartments.

$$
\begin{aligned}
& \mathrm{Q}_{\mathrm{F}}=\left(\mathrm{m}_{\text {air }} \cdot \mathrm{Cp}_{\text {air }} \cdot \Delta \mathrm{T}\right)_{\mathrm{F}} \\
& \mathrm{Q}_{\mathrm{R}}=\left(\mathrm{m}_{\text {air }} \cdot \mathrm{Cp}_{\text {air }} \cdot \Delta \mathrm{T}\right)_{\mathrm{R}}
\end{aligned}
$$

For convenience purposes, Eq. (4) and (5) were used in Watts, that is, divided by the refrigeration system's load time $\left(\mathrm{t}_{\mathrm{C}}\right)$. Thus:

$$
\begin{aligned}
& \mathrm{q}_{\mathrm{F}}=\frac{\left(\mathrm{m}_{\text {air }} \cdot \mathrm{Cp}_{\text {air }} \cdot \Delta \mathrm{T}\right)_{\mathrm{F}}}{\mathrm{t}^{\mathrm{C}}} \\
& \mathrm{q}_{\mathrm{R}}=\frac{\left(\mathrm{m}_{\text {air }} \cdot C \mathrm{Cp}_{\text {air }} \cdot \Delta \mathrm{T}\right)_{\mathrm{R}}}{\mathrm{t}^{\mathrm{C}}}
\end{aligned}
$$

The air mass $\left(\mathrm{m}_{\mathrm{air}}\right)$ is calculated based on the air density $(\rho)$, in terms of the mean temperature $\left(T_{m}\right)$ obtained during the experiment period and of the volume of the two refrigerator compartments. The Eq. (6) below is valid only within the range from $200 \mathrm{~K}$ to $400 \mathrm{~K}$, so:

$$
\rho\left(\mathrm{T}_{\mathrm{m}}\right)=\left(\frac{351.99}{\mathrm{~T}_{\mathrm{m}}}\right)+\left(\frac{344.84}{\left(\mathrm{~T}_{\mathrm{m}}\right)^{2}}\right)
$$

In order to calculate the specific heat $\left(\mathrm{C}_{\mathrm{P}}\right)$, the mean temperature $\left(\mathrm{T}_{\mathrm{m}}\right)$ is also utilized, obtained during the experiment. The Eq. (7) below is valid only within the temperature range from $200 \mathrm{~K}$ to $400 \mathrm{~K}$, so:

$$
\begin{aligned}
\mathrm{C}_{\mathrm{P}}\left(\mathrm{T}_{\mathrm{m}}\right)=1030.5-0.1995 & \cdot\left(\mathrm{T}_{\mathrm{m}}\right)^{2} \\
& +3.9734 \times 10^{-4} \cdot\left(\mathrm{T}_{\mathrm{m}}\right)^{2}
\end{aligned}
$$

After calculating the amount of heat removed from the freezer and the refrigerator, it becomes necessary to find the heat flow that enters through the refrigerator walls $\left(\mathrm{q}_{\mathrm{pt}}\right)$ to find total heat $\mathrm{q}_{\mathrm{L}}$, that is:

$$
\mathrm{q}_{\mathrm{L}}=\mathrm{q}_{\mathrm{F}}+\mathrm{q}_{\mathrm{R}}+\mathrm{q}_{\mathrm{Pt}}
$$

In this case, since it is possible to find thermal conductivity values for expanded polyurethane in literature $(\mathrm{K}=0.02 \mathrm{~W} / \mathrm{m} . \mathrm{K})$, it is easy to calculate the 
heat transfer rate through the refrigerator walls. It is thus necessary to use five thermocouples, two attached to the internal and external wall of the freezer, two attached to the internal and external wall of the refrigerator and one in the condenser region on the external wall of the refrigerator. Since these are Duplex refrigerators, the walls that will be analyzed have variable thicknesses. The heat transfer rate is thus calculated separately according to the variation in isolation thickness in each compartment in question, as illustrated in Tab. 1.

Table 1. Areas and thicknesses for each compartment.

\begin{tabular}{|c|c|c|c|c|}
\hline \multirow{3}{*}{ 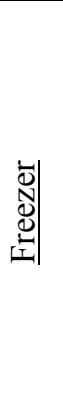 } & Place: & $\begin{array}{l}\text { Top } \\
\text { and } \\
\text { sides }\end{array}$ & $\underline{\text { Door }}$ & $\underline{\text { Backside }}$ \\
\hline & Area $\left(\mathrm{m}^{2}\right)$ : & 0.516 & 0.1728 & 0.1728 \\
\hline & $\begin{array}{c}\text { Insulation } \\
\text { Thickness } \\
\text { (m): }\end{array}$ & 0.06 & 0.075 & 0.075 \\
\hline \multirow{3}{*}{ 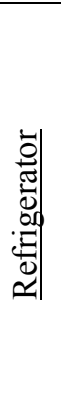 } & Place: & $\begin{array}{l}\underline{\text { Base }} \\
\underline{\text { and }} \\
\text { sides }\end{array}$ & $\underline{\text { Door }}$ & $\underline{\text { Backside }}$ \\
\hline & Area $\left(\mathrm{m}^{2}\right)$ : & 1.311 & 0.6264 & 0.6264 \\
\hline & $\begin{array}{c}\text { Insulation } \\
\text { Thickness } \\
\text { (m): }\end{array}$ & 0.03 & 0.45 & 0.45 \\
\hline
\end{tabular}

Thus, the following equations are used to calculate the heat transfer rates that penetrate through the refrigerator walls:

$$
\begin{aligned}
& \mathrm{q}_{\mathrm{PtF}}=\frac{\mathrm{K} \cdot(\mathrm{A} \cdot \Delta \mathrm{T})_{\mathrm{F}}}{\mathrm{e}_{\mathrm{F}}} \\
& \mathrm{q}_{\mathrm{PtR}}=\frac{\mathrm{K} \cdot(\mathrm{A} \cdot \Delta \mathrm{T})_{\mathrm{R}}}{\mathrm{e}_{\mathrm{R}}}
\end{aligned}
$$

Using Eq. (9) and (10) for each location on the refrigerator and adding the rates that refer to each wall of the freezer and refrigerator compartments, the heat transfer rate that enters through the refrigerator walls is obtained:

$$
\mathrm{q}_{\mathrm{Pt}}=\mathrm{q}_{\mathrm{PtF}}+\mathrm{q}_{\mathrm{PtR}}
$$

Therefore, replacing Eq. (11) in Eq. (8), the refrigerator's useful refrigeration is calculated $\left(\mathrm{q}_{\mathrm{L}}\right)$.

The energy consumed by the refrigerator with a modified heat exchanger is obtained by means of a
SAGA4000 equipment, model 1380, which is an electronic recorder of monophase or triphase portable electric systems in distribution networks, to be installed outside or in various low tension circuits.

With the utilization of such equipment, it is possible to obtain the energy wasted [W.h] by the refrigerator during the experiments. Due to the consumption unit [W.h] presented by the equipment, it is necessary to divide the value obtained by the experiment performance time, in hours, thus obtaining the consumption in Watts.

After making the referred to conversions, it is possible to determine the COPS for the modified refrigerator using the following equation:

$$
\mathrm{COPS}=\frac{\mathrm{q}_{\mathrm{L}}}{\mathrm{W}}
$$

\section{RESULTS}

A) Behavior of the refrigeration cycle for the modified refrigerator.

Figure 2 shows the modified refrigerator's refrigeration cycle temperature profiles operating at maximum power over a 24 hour period.

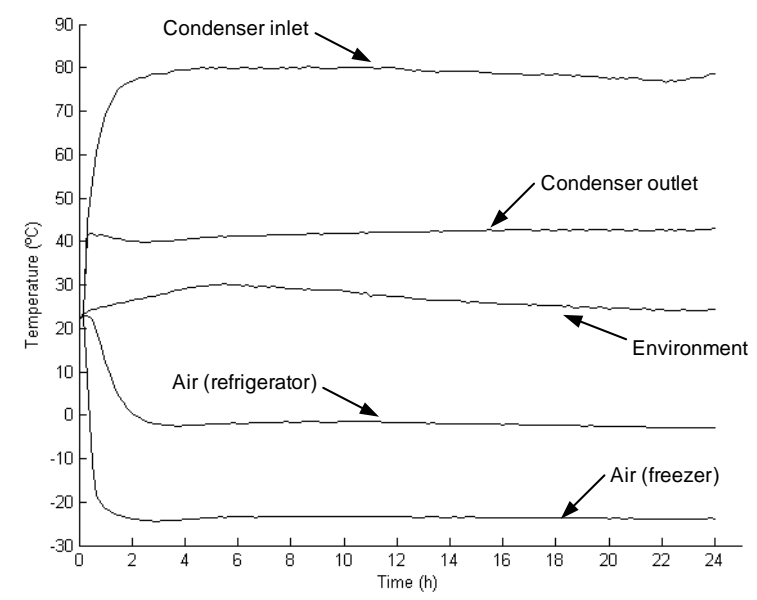

Figure 2. Modified refrigerator's refrigeration cycle temperature profiles operating at maximum power.

Upon analyzing the refrigeration cycle temperature profiles, illustrated in Fig. 2, it is observed that the compressor's output temperature is approximately $40^{\circ} \mathrm{C}$, however the input temperature is significantly higher at $80^{\circ} \mathrm{C}$. The refrigeration and freezing compartments, respectively, have temperature levels of $-2^{\circ} \mathrm{C}$ and $-23^{\circ} \mathrm{C}$, after stability and without any load, that is, the compartments are empty. From the temperature values obtained at the walls of the compartments to be refrigerated, Fig. (3) and (4), reveal the behavior of the heat flow profiles that refer to the freezer and refrigerator, respectively.

Based on Fig. (3) and (4), an accentuated increase in heat flow profiles can be observed through the 
freezer compartment walls when compared to the respective refrigerated compartment profiles. This increase can be attributed to the temperature levels reached in each compartment, favoring a greater flow in the freezer compartment, which has a greater temperature difference compared to the external environment.

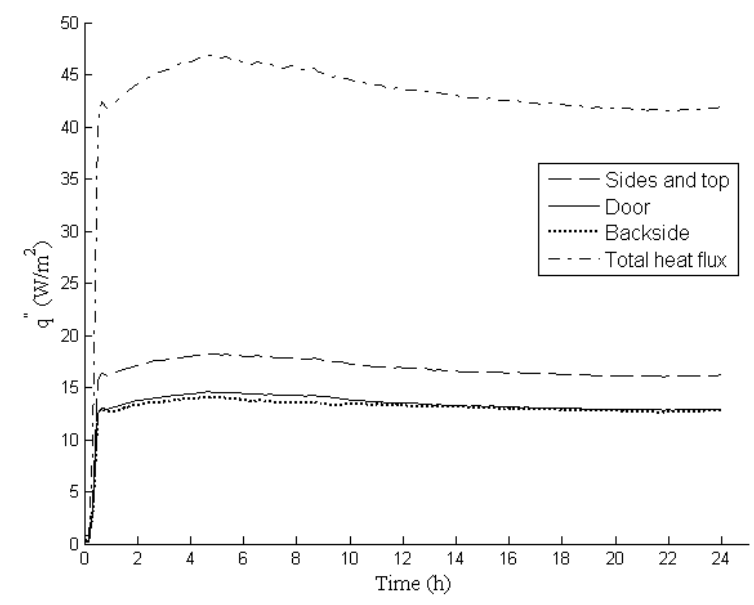

Figure 3. Heat flows through freezer compartment walls.

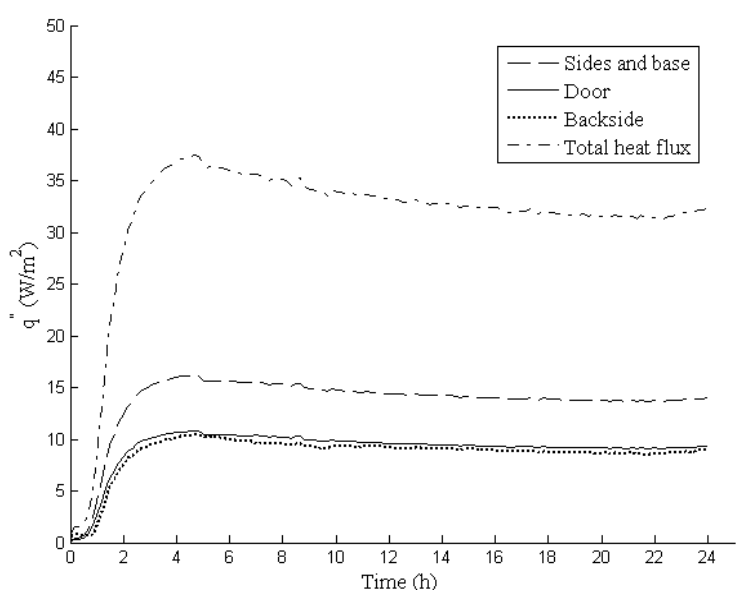

Figure 4. Heat flows through refrigerated compartment walls.

Table 2. Amount of energy that influences in the refrigeration system's COPS.

\begin{tabular}{|c|c|c|c|}
\hline $\begin{array}{c}\text { Modified } \\
\text { refrigerator }\end{array}$ & $\begin{array}{c}\text { Refrigerator } \\
{[\mathrm{J}]}\end{array}$ & Freezer $[\mathrm{J}]$ & Total $[\mathrm{J}]$ \\
\hline $\begin{array}{c}\text { Heat that } \\
\text { entrers in } \\
\text { the system }\end{array}$ & 2723777.56 & 1137115.44 & 3860893.0 \\
\hline $\begin{array}{c}\text { Removed } \\
\text { heat of the } \\
\text { system }\end{array}$ & -8180.07 & -4427.96 & -12608.03 \\
\hline $\begin{array}{c}\text { Eletric } \\
\text { energy } \\
\text { consumed }\end{array}$ & 0.00 & 0.00 & $\begin{array}{c}10562400 . \\
0\end{array}$ \\
\hline COPS & 0.00 & 0.00 & 0.37 \\
\hline
\end{tabular}

From the obtained heat flows, Tab. (2), shown below, illustrates the amount of heat that enters the system through the refrigerator walls, the amount of heat removed from the each compartment's air, the power consumed during testing and finally the COPS, related to the modified refrigerator.

B) Analysis of thermal storage load dynamics.

During the testing illustrated in Fig. (2), a temperature variation of approximately $39^{\circ} \mathrm{C}$ can be seen between condenser input and output. Thus, when using water to condense the coolant in the modified condenser, the thermal energy absorbed by the water is stored through the thermosyphon principle. Thus, Fig. (5) shows temperature's evolution as a function of time during a 24-hour test.

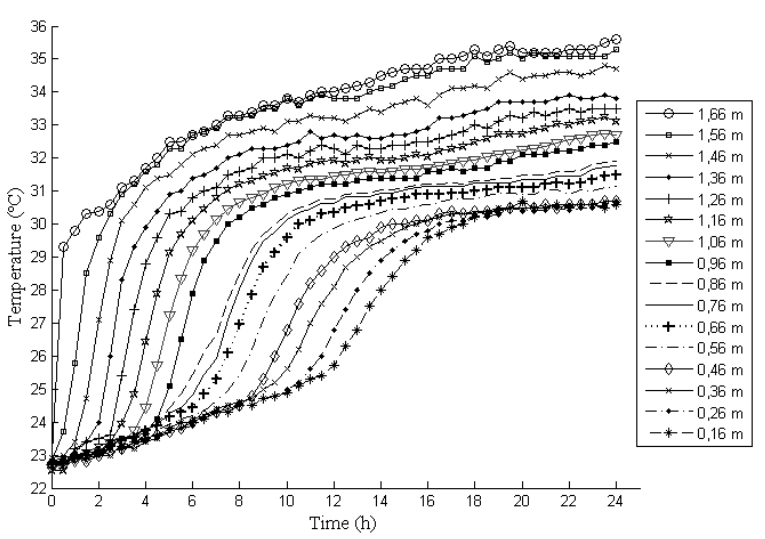

Figure 5. Evolution of temperature profiles as a function of time inside the thermal storage.

According to the position of the thermocouples (Fig. 5), the temperature profile gradients can be seen according to their height, with higher energy levels for those thermocouples located in the top region of storage area, and lower energy levels for those located near the base.

The Fig. 6 shows the behavior of the temperature profiles according to the position of the thermocouples distributed along the height of the tank, for each hour of testing.

Based on Fig. 6, the initial curve for $\mathrm{t}=0$ hour can be observed. It indicates the temperature profile for the initial instant when all the water in the storage region has a nearly constant temperature, which is also less than ambient temperature. As time goes by, the dynamic behavior of the isoclines can be observed through the thermal stratification effect until it reaches full load.

Approximately 17 hours after beginning the test, the thermal storage containing water is completely loaded, however the temperature variation between the base and the top is approximately $5^{\circ} \mathrm{C}$, due to losses caused by conduction and convection between the water and the environment, respectively. 


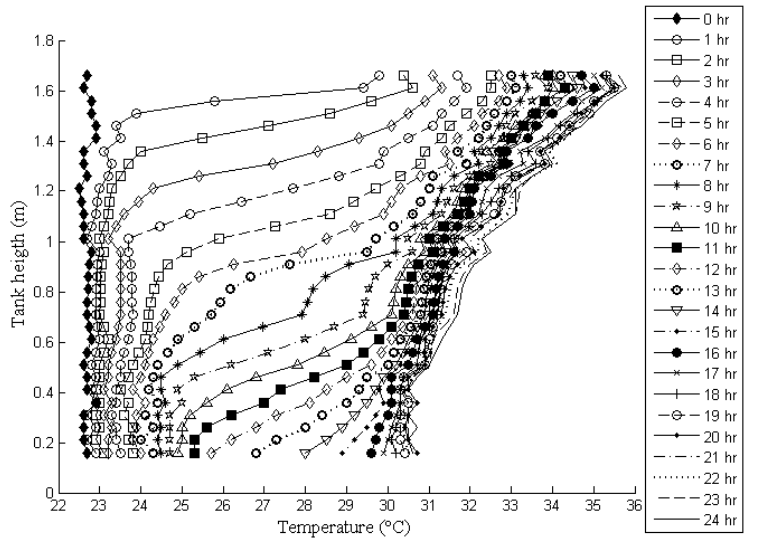

Figure 6. Behavior of the temperature profiles according to the position of the thermocouples distributed along the height of the tank.

\section{CONCLUSIONS}

It was possible to observe the full operation of the modified refrigeration system, which did not reveal significant alterations in thermodynamic behavior after the modifications made on the condenser.

Since this is a conventional domestic refrigeration system, the amount of hot water produced and the thermal storage container loading time were satisfactory. The dynamic behavior of the thermoclines was observed according to the thermal stratification effect and the evolution of temperatures as a function of time, throughout the test inside the thermal storage container. These are fundamental variables in comparative analyses of conventional refrigerators.

\section{REFERENCES}

Amaral Filho, P. H. F., 2005, Aproveitamento do rejeito térmico de condensadores em sistemas de refrigeração, Master Thesis, Universidade Estadual Paulista Júlio de Mesquita Filho, Bauru, SP.

Fernández-Seara, J., Uhía, F. J., and Sieres, J., 2007, Experimental analysis of a domestic eletric hot water storage tank. part i: static mode of operation, Applied Thermal Engineering, Vol. 27, No. 1, pp. 129-136.

Fernández-Seara, J., Uhía, F. J., and Sieres, J., 2007, Experimental analysis of a domestic eletric hot water storage tank. part ii: dynamic mode of operation, Applied Thermal Engineering, Vol. 27, No. 1, pp. 137-144.

Jiang, H., Jiang, Y., Wang, Y., Ma. Z., and Yao, Y., 2006, An experimental study on a Modified Air Conditioner With a Domestic Hot Water Supply, Energy, Vol. 31, No.12, pp. 1789-1803.

Kandari, A. M.,1990, Thermal Stratification in Hot Storage-tanks, Applied Energy, Vol. 35, pp. 299315.

Padilha, A., 1982, Estocagem por Estratificação Térmica de Líquido em Reservatório, in: I Congresso
Latino Americano de Transferência de Calor e Massa, La Plata, Argentina, pp. 934-949.

Padilha, A., 1983, Estocagem por Estratificação Térmica de Líquido em Reservatório, Master Thesis, Universidade Federal do Rio de Janeiro, Rio de Janeiro, RJ.

Stoecker, W. F., and Jones, J. W., 1985, Refrigeração e Ar Condicionado, McGraw-Hill do Brasil Ltda.

Trillat-Berdal, V., Souyre, B., and Fraisse, G., 2006, Experimental Study of a Ground-coupled Heat Pump Combined With Thermal Solar Collectors, Energy and Buildings, Vol. 38, No. 12, pp. 14771484.

Van Wylen, G. J., Sonntag, R. E., and Borgnakke, C., 2003, Fundamentos da Termodinâmica, Edgard Blücher Ltda. 